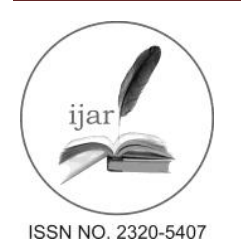

Journal homepage:http://www.journalijar.com
Journal DOI:10.21474/IJAR01

RESEARCH ARTICLE

\title{
DESIGN AND ANALYSIS OF WORK HOLDING DEVICE FOR MILLING OPERATION ON FRONT AXLE BEAM (HCV).
}

\author{
*Sanket B. Mahind ${ }^{1}$, Ruturaj S. Surve ${ }^{1}$, Siddheshwar P. Jadhav ${ }^{1}$ and Shubham S. Waykar ${ }^{1}$, Ujwal Gawai ${ }^{2}$. \\ 1. Department of Mechanical Engineering,JSPM's Imperial college of Engineering and Research, Wagholi, Pune, \\ Maharashtra, India. \\ 2. Assistant professor, Department of Mechanical Engineering, JSPM's Imperial college of Engineering and \\ Research, Wagholi, Pune, Maharashtra, India.
}

\section{Manuscript Info}

\section{Manuscript History:}

Received:18 March 2016

Final Accepted: 22 April 2016

Published Online: May 2016

Key words:

Work holding device,

Front axle beam,

*Corresponding Author

Sanket B. Mahind.

\begin{abstract}
Over the past century, automotive mass production has increased the demand for forged components .Front axle is the major component in an automotive chassis. The work holding was the first issue of the machining operation to be confronted. In machining work holding devices, minimized work piece deformation due to proper clamping and cutting force which was essential to maintain the machining accuracy. This paper gives detailed description on designing a work holding device so that milling operation was performed properly to obtain required dimension for a front axle beam used in automotive application. It also includes the detailed result of analysis done for the assembled devices and also to known the behaviour of the work holding devices against the operating load. The proposed work holding device is designed, to increase the accuracy of machining process so that it can be machining easily with lesser time and in turns its saves the machining time, manufacturing cost and increases the productivity.
\end{abstract}

Copy Right, IJAR, 2016,. All rights reserved.

\section{Introduction:-}

Increasing the productivity and accuracy are the two basic aims of mass production. In this case the device that caters our needs is the use work holding device. As we all know the work holding device is a special tool for holding a work piece in proper position during manufacturing operation. For supporting and clamping the work piece, device is provided. Frequent checking, positioning, individual marking and non-uniform quality in manufacturing process is eliminated by fixture. This increase machining accuracy, productivity and reduce operation time, but the main concern is the fastening of the fixture. The fixture should be so chosen that the fastening of the job to the table is done quickly and accurately and it is mainly used in milling operation. Work holding device is widely used in the industrial practical production. To locate and immobilize workpieces for machining, inspection, assembly and other operations work holding devices are used. Work holding device are used to determine the position and orientation of a workpiece; Clamping has to be appropriately planned at the stage of machining fixture design. The design of a work holding device is a highly complex and intuitive process, which require knowledge. Work holding device designplays an important role at the setup planning phase. Proper work holding device design is crucial for developing product quality in different termsof accuracy, surface finish and precision of the machined parts in existing design the fixture set up is done manually, so the aim of this project is to increase the machining accuracy of front axle beam and to save time for loading and unloading of component. These work holding device also help in simplifying the network operations which are performed on special equipment. 


\section{Design considerations:-}

The points that are taken into consideration for designing a product are as following:

1. Work holding device should be so strong that the deflection in the device should be as less as possible. The deflection that includes the forces of cutting, clamping of workpiece to the machine table. The frame of the fixture should have sufficient mass to prevent vibrations during the machining of the job.

2. Another important design consideration is the clamping which should be fast enough.

3. Require less amount of effort and they should also have the arrangement for easy removal as well.

4. In swinging of clamp system is provided so that while removal of workpiece the clamp should swing as far as possible for unclamping the device.

5. The clamps and support points which are to be adjusted in due course of time should be preferred of same size.

6. If the surface area of clamping is more it will not fit the workpiece properly. This can be avoided by making the surface area of clamping as small and proper size as possible.

7. It is designed in such a way that pats can be easily replaced on failure of device.

8. The study of the design should be done thoroughly before analysis and designing. It should always be ensured that the work is done in proper sequence and order. This will ensure zero error during designing pats in NX software and during ansys stress acting.

9. It has been preferred that there is maximum operation in a single setting of the holding device.

10. The movement of the holding device is restricted i.e. there is zero degree of freedom of the workpiece after clamping the workpiece.

11. The design must possess enough rigidity and robustness to prevent vibration else it may lead to undesired movement of the workpiece and tools.

12. Minimum cost should be done during the fabrication of the project and the design should be as simple as possible.

\section{Component Details:-}

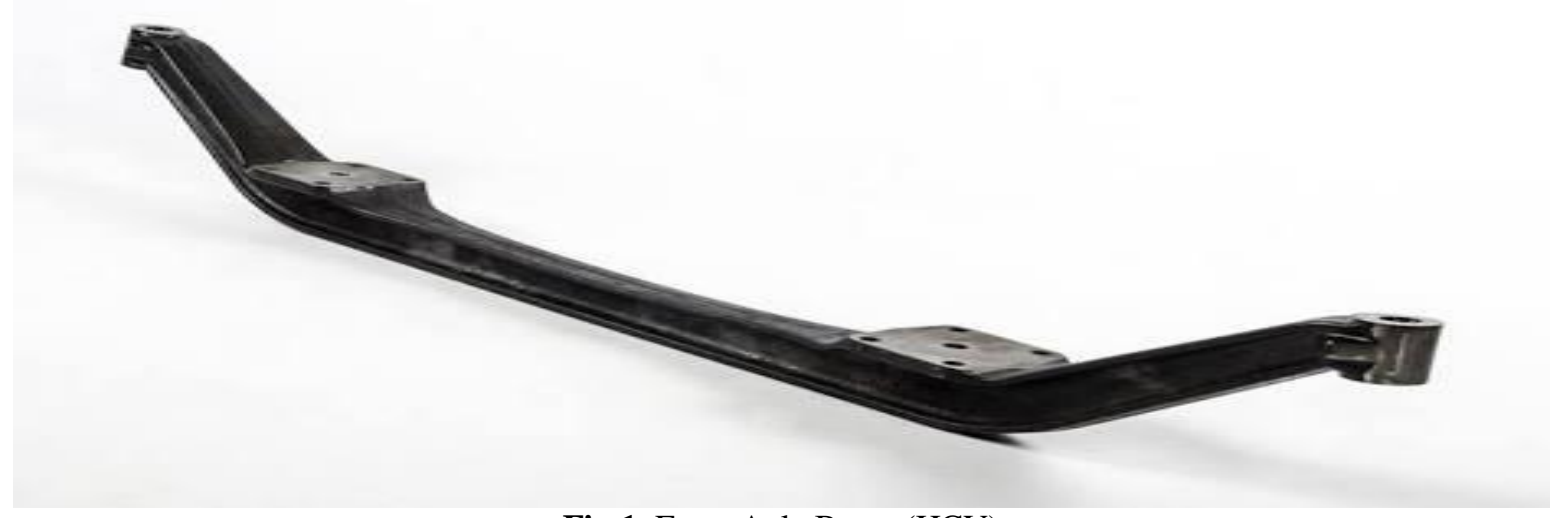

Fig.1. Front Axle Beam (HCV)

This component is used in automotive applications. The component is made up of

Table.No.1

\begin{tabular}{|l|c|}
\hline Name & Front axle beam (HCV) \\
\hline Material & S 58C \\
\hline Component weight & $114.5 \mathrm{~kg}$ \\
\hline $\begin{array}{l}\text { Yield } \\
\text { tensile strength }\end{array}$ & 324 \\
\hline Thermal expansion & $11.9 \mu \mathrm{m} / \mathrm{m}-\mathrm{k}$ \\
\hline Density & $7.8 \mathrm{gm} / \mathrm{cm}^{2}$ \\
\hline
\end{tabular}




\section{Design of Work Holding Device:-}

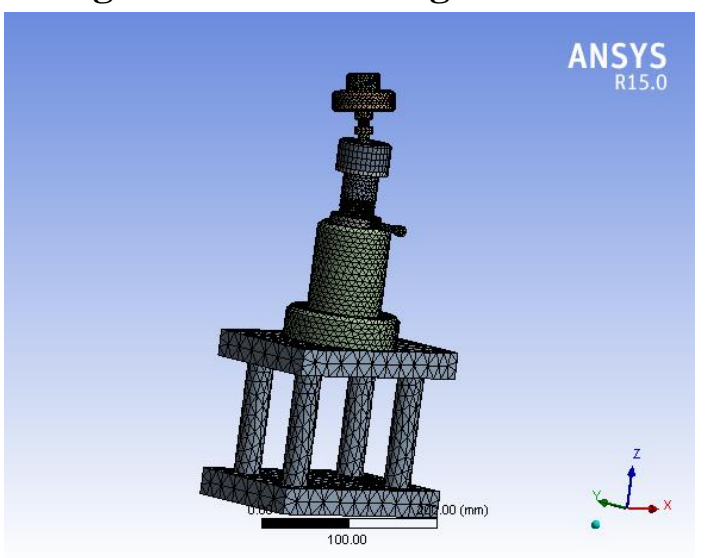

Force acting on the work holding device is $\left(\mathrm{R}_{\mathrm{B}}\right)$ -

$$
\begin{aligned}
\mathrm{R}_{\mathrm{B}} & =\frac{\text { Weight of front axle beam }(\mathrm{N})}{2 * \text { Inclination of front axle beam to the work holding device }} \\
& =\frac{114.5 * 9.81}{2 * \cos \left(\frac{111)}{1(11)}=561.22 \mathrm{~N}\right.}
\end{aligned}
$$

Various elements of a work holding devices are as follows
i. Power screw
ii. Spring
iii. Spherical rolling joint

\section{Design of power screw:-}

\section{Given data:-}

Force, $\mathrm{F}=561.22 \mathrm{~N}$

$162=\frac{57.25 * 9.81 / \cos 11}{\frac{\pi}{4} * \mathrm{~d}_{\mathrm{c}}{ }^{2}}$

$$
\sigma_{c=\frac{w}{4} \mathrm{~d}^{2}}
$$

$\mathrm{d}_{\mathrm{c}}{ }^{2}=\frac{572.1342}{127.23} \mathrm{~d}_{\mathrm{c}}=2.1205 \mathrm{~mm}$

Normal series of power screw start

- $\quad$ Square head:- $d=22 \mathrm{~mm}$

$\mathrm{p}=5 \mathrm{~mm}$

- Trapezoidal thread - $\mathrm{d}=24 \mathrm{~mm}$

$\mathrm{p}=5 \mathrm{~mm}$

$D_{\mathrm{i}}=\mathrm{d}=24 \mathrm{~mm}$

$\mathrm{P}=5 \mathrm{~mm}$

$\mathrm{D}_{\mathrm{o}}=\mathrm{D}=\mathrm{d}+\mathrm{p}=29 \mathrm{~mm}$

$\mu=0.12-0.15=0.13$

$\mu_{\mathrm{c}}=0.12-0.18=0.15$

$\tau=\rho * \frac{d_{m}}{2}$

$\rho=\mathrm{w} * \tan (\mathrm{k} \varphi+\alpha)$

$$
\varphi=\tan ^{-1}\left(\frac{1}{\pi d_{m}}\right)
$$

$$
\begin{aligned}
& =\tan ^{-1}\left(\frac{5}{\pi(26.5)}\right) \quad=3.4369^{0} \\
& \rho=\mathrm{W} * \tan (\mathrm{l}(\varphi+\alpha)
\end{aligned}
$$




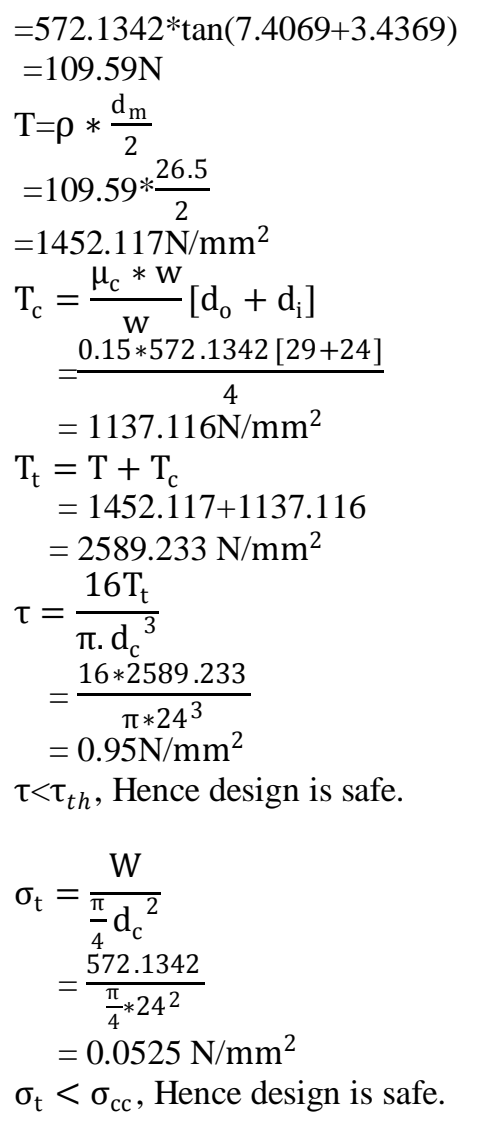

\section{Design of spring:-}

\section{Given:-}

Force $\mathrm{F}=561.22 \mathrm{~N}$

Material $=$ Carbon steel wires oil-tempered wire.

$\mathrm{C}=0.6-0.7$

$\mathrm{Mn}=0.6-0.9$

Yield strength $=1400 \mathrm{~N} / \mathrm{mm}^{2}$

Tensile strength $=420 \mathrm{~N} / \mathrm{mm}^{2} \ldots \ldots \ldots \ldots \ldots \ldots$ (Machine design S.S Wadhwa)

For the direct all loading $\mathrm{W}=572.1342 \mathrm{~N}$

$$
\begin{aligned}
& K_{w}=\frac{4 C-1}{4 C-4}+\frac{0.615}{C} \\
& =\frac{4 * 5-1}{4 * 5-4}+\frac{0.615}{5} \\
& =1.3105 \\
& \tau=\frac{8 W C}{\pi d^{2}} * K_{w} \\
& 420=\frac{8 * 572.1342 * 5 * 1.3105}{\pi d^{2}} \\
& d^{2}=19.56 \\
& \mathrm{~d}=4.36 \mathrm{~mm} \approx 4.5 \mathrm{~mm} \\
& \text { Spring Index } \\
& \mathrm{C}=\frac{D}{d} \quad \mathrm{D}=\mathrm{C} * \mathrm{~d}=4.5 * 5=22.5 \mathrm{~mm}
\end{aligned}
$$


The spring is design for only the swiveling mechanism $\&$ the swiveling mechanism till upto $30^{0}$

$$
\begin{aligned}
\delta & =\frac{D}{2} * \theta \\
& =\frac{22.5}{2} * 30 * \frac{\pi}{180} \\
& =5.89
\end{aligned}
$$

$$
\theta=30^{0}
$$

Stiffness (K)

$$
\begin{aligned}
\mathrm{K} & =\frac{w}{\delta} \\
& =\frac{572.1342}{5.89} \\
& =97.1365 \\
\mathrm{k} & =\frac{G d}{8 C^{3} n} \\
& =\frac{80 * 10^{3} * 5}{8 * 5^{3} * n} \\
& =5
\end{aligned}
$$

Total number of coils

for square \& ground ends, the number of in active coils is 2

$$
\begin{aligned}
\mathrm{N} & =\mathrm{n}+2 \\
& =5+2 \\
& =7 .
\end{aligned}
$$

Design of spherical rolling joint:-

Spherical rolling joint is selected from the standard design based on total load acting on the joint as shown in below-

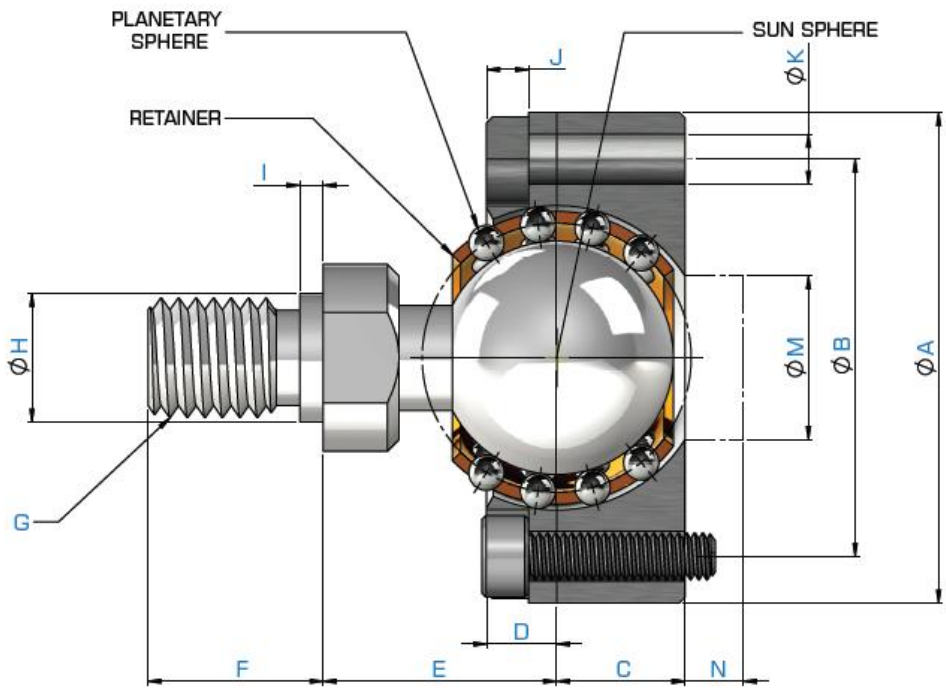

Fig.2. Spherical Rolling Joint. 
Table.No. 2:-

\begin{tabular}{|c|c|c|c|c|c|c|c|}
\hline \multirow[t]{2}{*}{ MODEL } & \multirow{2}{*}{$\begin{array}{l}\text { SHAFT THREAD } \\
\text { RECOMMENDED } \\
\text { TORQUE (N-m) }\end{array}$} & \multicolumn{2}{|c|}{$\begin{array}{l}\text { COMPRESSIVE } \\
\text { LOADS }\end{array}$} & \multicolumn{2}{|c|}{ TENSILE LOADS } & \multirow{2}{*}{$\begin{array}{c}\text { WEIGHT } \\
(\mathrm{kg})\end{array}$} & \multirow{2}{*}{$\begin{array}{l}\text { MAXIMUM } \\
\text { SWING } \\
\text { ANGLE }\end{array}$} \\
\hline & & $C(\mathrm{Nm})$ & $\mathrm{Co}(\mathrm{Nm})$ & $\mathrm{T}(\mathrm{Nm})$ & To (Nm) & & \\
\hline SRJ004C & 0.6 & 128 & 100 & 38.4 & 30 & 0.015 & $\pm 15^{\circ}$ \\
\hline SRJ006C & 1.57 & 320 & 280 & 96 & 84 & 0.036 & $\pm 30^{\circ}$ \\
\hline SRJ008C & 3.22 & 490 & 540 & 147 & 162 & 0.06 & $\pm 30^{\circ}$ \\
\hline SRJ012C & 23.19 & 720 & 770 & 216 & 231 & 0.18 & $\pm 30^{\circ}$ \\
\hline SRJ016C & 40.45 & 1170 & 1300 & 351 & 390 & 0.37 & $\pm 30^{\circ}$ \\
\hline SRJ024C & 64.37 & 2840 & 3920 & 852 & 1176 & 0.93 & $\pm 30^{\circ}$ \\
\hline SRJ032C & 100.44 & 5800 & 8820 & 1740 & 2646 & 2.30 & $\pm 30^{\circ}$ \\
\hline SRJ048C & 600.08 & 10600 & 16000 & 3180 & 4800 & 6.73 & $\pm 30^{\circ}$ \\
\hline
\end{tabular}

\section{Result and Discussion:-}

The model is designed in $\mathrm{Nx}$ and analyzed in ansys software. This software is capable of giving the user post deformation and stress on the model after applying a force. This result include maximum principal stress, von-mises stress and total deformation stress along $\mathrm{x}, \mathrm{y}, \mathrm{z}$ axes. By considering the milling operation on SPM we analyzed that due to proper clamping of front axle beam with help of work holding device the accuracy of KP top face milling operation of front axle beam increases. Hence the following result has been achieved using work holding device.

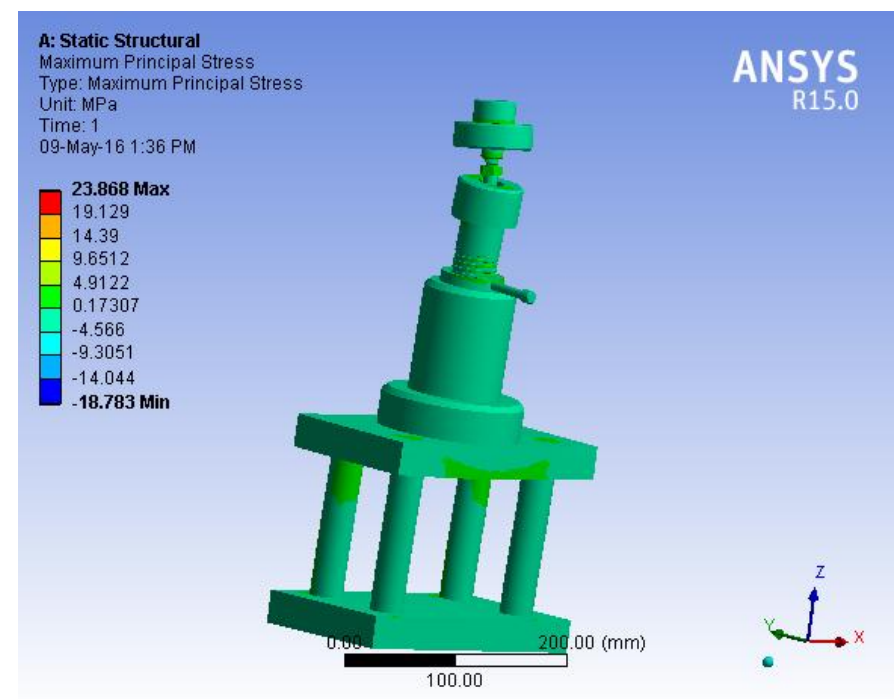

Fig.3.Maximum Principal Stress 


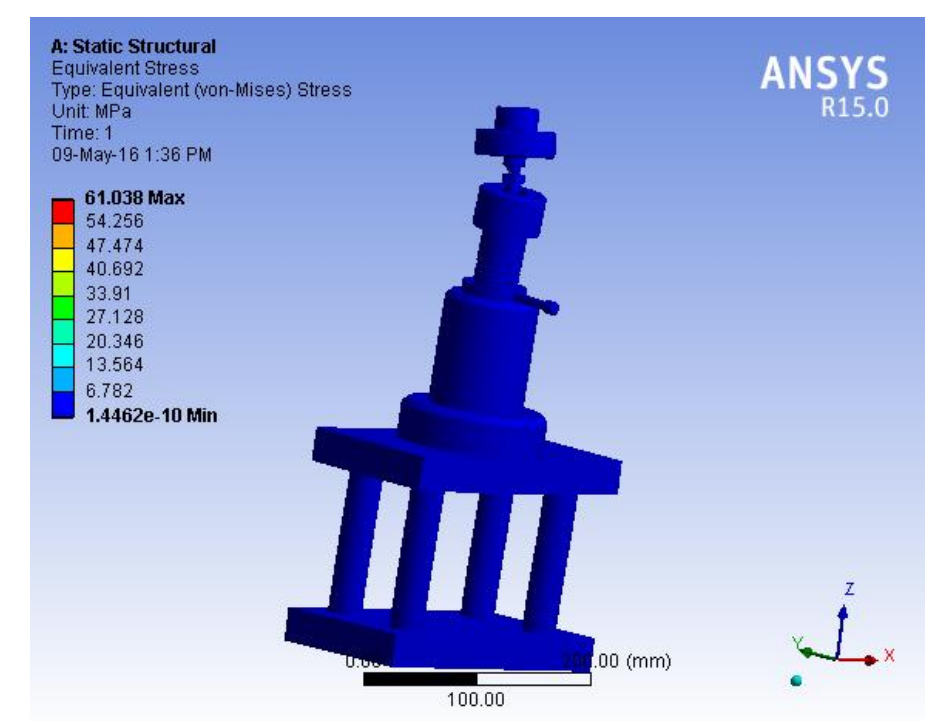

Fig.4. Equivalent Stress

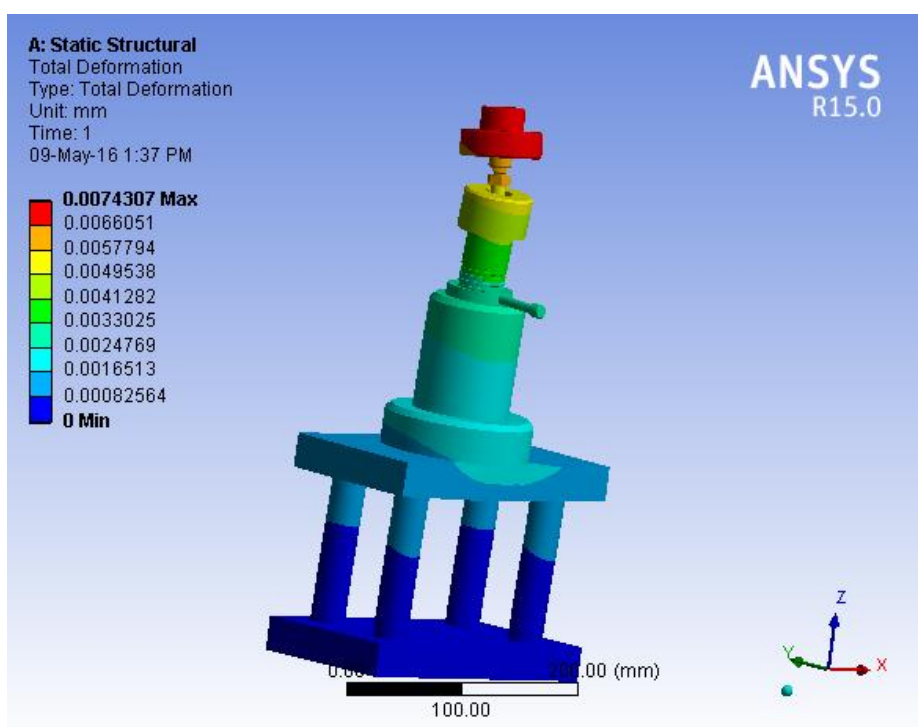

Fig.5.Total Deformation stress.

\section{Conclusion:-}

Observing clearly the milling operation on special purpose machine we have concluded that, the Squareness of KP top face with bore of front axle beam which was out of tolerance because the locators are placed on rough surface. For this the outcome of work is to place the work holding device on prefinished surface due to which the errors are minimized as well as loading and unloading time decreases and increase in productivity simultaneously. For this operation, new work holding device was designed using screw jack and spherical rolling joint with helical compression spring mechanism for best accuracy. 


\section{References:-}

1. SupriyaBurgul(2014), Literature Review on Design, Analysis and Fatigue Life of a Mechanical Spring ,IJRAME.

2. Pritam Kumar Kundu(2014),Design and fabrication of work holding device for a drilling machine.

3. Alec Robertson, Adam Rzepniewski, Alexander Slocum,Measurement and Calibration of High Accuracy Spherical Joints.

4. HENRY P. SWIESKOWSKI(1979), Design of Helical Compression Sprrings, Us Army Armament Research And, DevelopmentComnand.

5. Dr.A.Pandhare, AakashDorwat, AtulShirode(2015),Swivelling Mechanism Design and Manufacturing,IJERGS.

6. SonuYadav ,M.L.Aggarwal(2014),Effect of Lifting Load on Solar Powered Screw Jack Design In Automotive Vehicles,IJSRD 